\title{
A Positive Theory of Fiscal Deficits and Government Debt
}

\section{Citation}

Alesina, Alberto, and Guido Tabellini. 1990. A positive theory of fiscal deficits and government debt. Review of Economic Studies 57, no. 3: 403-414.

\section{Published Version}

http://dx.doi.org/10.2307/2298021

\section{Permanent link}

http://nrs.harvard.edu/urn-3:HUL.InstRepos:3612769

\section{Terms of Use}

This article was downloaded from Harvard University's DASH repository, and is made available under the terms and conditions applicable to Other Posted Material, as set forth at http:// nrs.harvard.edu/urn-3:HUL.InstRepos:dash.current.terms-of-use\#LAA

\section{Share Your Story}

The Harvard community has made this article openly available.

Please share how this access benefits you. Submit a story.

Accessibility 
NBER WORKING PAPER SERIES

A POSITIVE THEORY OF FISCAL

DEFICITS AND GOVERNMENT

DEBT IN A DEMOCRACY

\author{
Alberto Alesina \\ Guido Tabellini
}

Working Paper No. 2308

NATIONAL BUREAU OF ECONOMIC RESEARCH

1050 Massachusetts Avenue

Cambridge, MA 02138

JuTy 1987

The research reported here is part of the NBER's research program in Financial Markets and Monetary Economics. Any opinions expressed are those of the authors and not those of the National Bureau of Economic Research. 
NBER Working Paper \#23D8

July 1987

A Positive Theory of Fiscal Deficits and Government Debt in a Democracy

\section{ABSTRACT}

This paper considers an economy in which policymakers with different preferences concerning fiscal policy alternate in office as a result of democratic elections. It is shown that in this situation government debt becomes a strategic variable used by each policymaker to influence the choices of his successors. In particular, if different policymakers disagree about the desired composition of government spending between two public goods, the economy exhibits a deficits bias. Namely, in this economy debt accumulation is higher than it would be with a social planner. According to the results of our model, the equilibrium level of government debt is larger: the larger is the degree of polarization between alternating governments; and the more likely it is that the current government will not be reelected. The paper has empirical implications which may contribute to explain the current fiscal policies in the United States and in several other countries.

Alberto Alesina

GSIA

Carnegie-Mellon University

Pittsburgh, PA 15213

and

National Bureau of Economic Research

1050 Massachusetts Avenue

Cambridge, MA 02138
Guido Tabellini

Department of Economics

UCLA

Los Angeles, CA 90D24 
"This deficit is no despised orphan. It's President Reagan's child, and secretly, he loves it, as David Stockman has explained: The deficit rigorously discourages any idea of spending another dime on social welfare". New York Times, January 25. 1987.

\section{INTRODUCTION}

Budget deficits and debt accummulation can serve two purposes: they provide a means of redistributing income over time and across generations; and they serve as a means of minimizing the deadweight losses of taxation associated with the provision of public goods and services. This paper focuses on the latter issue. Thus, as in Barro (1979), Brock-Turnovsky (1980) and Lucas-Stokey (1983), public debt is modeled as a means of distributing tax distortions over time.

Barro (1985), (1986), (1987) has shown that this normative theory of fiscal policy can explain quite well the behavior of public debt in the United States and in the United Kingdom. However, this theory may not provide a complete explanation of two recent facts: a) the rapid accumulation of government debt in several industrialized countries including the United States, in relatively peaceful times; b) the large variation in the debt policies pursued by different countries with similar economic conditions.

This paper attempts to explain these facts by removing the assumption that fiscal policy is set by a benevolent social planner who maximizes the welfare of a representative consumer. We consider an economy with two policymakers who randomily alternate in office and pursue different objectives. Different policymakers exist because the private agents have different views about fiscal policy and vote for their preferred policymaker. Thus we focus on a positive rather than a normative theory of fiscal policy. 1

The crucial point emphasized in this paper is that in this situation public debt is used strategically by each government to influence the choices of its successors. Thus, the time path of public debt is the result of the strategic interaction of different governments which are in office in different periods. This leads to fiscal policies which differ sharply from 
those which would be chosen by a social planner, certain of her future reappointment. 2

The main features of our model can be summarized as follows: there is a constant population of individuals with the same time horizon, acting as consumers, workers and voters. They are identical in all respects except in their preferences about two public goods, supplied by the goverrment and financed by means of distortionary taxes on labor. Different individuals have different preferences on the composition of public consumption. The policymaker is appointed at discrete intervals by means of democratic elections, and is chosen among two candidates (or "political parties"). Each party maximizes the utility function of a different group of consumers (its "constituency"). Alternatively, one may interpret the disagreement between the policymakers in terms of different "ideological" views about social welf are.

This paper shows that the equilibrium stock of debt tends to be larger than with a benevolent social planner certain of her future reappointment. Intuitively, disagreement among alternating governments and uncertainty about the elections' outcome prevent the party in office from fully internalizing the cost of leaving debt to its successors. This suggests the possible existence of a deficit bias in democracies (or with any other form of government where alternation between different policymakers is possible). More genera $11 y$, our paper suggests that differences in political institutions can contribute to explain the variance in the debt policies pursued by different countries or by the same country at different points in time. According to the results of our model, the equilibrium level of public debt tends to be larger: (i) the larger is the degree of polarization between alternating governments; (ii) the more likely it is that the current government will not be reappointed; (iii) the more likely it is that the government is constrained to provide at least a minimum level of each kind of public good. These implications of the model are, in principle, empirically testable.

The outline of the paper is as follows: the model is presented in Section 2. Section 3 analyzes its static properties. The optimal and time consistent fiscal policies of an hypothetical social planner are described in section 4. Sections 5 and 6 characterize the dynamic economic and political equilibrium in a two period version of the model. Sections 7 and 8 extend the 
basic model by considering its infinite horizon version and more general specifications of the policymakers' objective functions and constraints. The conclusions and the normative implications of our analysis are summarized in the final section.

\section{THE MODEL}

The model is derived from Lucas-Stokey (1983). There is a constant population of $\mathrm{N}$ individuals, acting as consumers, workers and voters. All of them are born at the beginning of period zero and have the same time horizon. We consider both the finite horizon case (two periods) and the infinite horizon case. Consumer $i$ has the following separable objective function, $w^{i}$ :

$$
w^{i}=E_{0}\left\{\sum_{t=0}^{T} \delta^{t}\left[u\left(c_{t}^{i}\right)+v\left(x_{t}^{i}\right)+\alpha_{1} h\left(g_{t}\right)+\left(1-\alpha_{i}\right) h\left(f_{t}\right)\right]\right\} ; 1>\delta>0 ;
$$

where $c$ is private consumption; $x$ is leisure time; $g$ and $f$ are two different public goods in per capita terms; and $\delta$ is the discount factor. The functions $u(\cdot), v(\cdot)$ and $h(\cdot)$ are continuous, at least three times continuously differentiable, strictly increasing and strictly concave. $E_{0}$ is the expectation operator conditional on the information set available at time 0 . Each consumer is identified only by her preference on the two public goods; this difference is parameterized by the coefficient $\alpha_{i}$. Note that $\alpha_{i}$ is not constrained to lie in the interva] $[0,1]$. Some consumers may attribute negative utility to certain types of public goods, such as military expenditure.

Each consumer is endowed with one unit of labor that can be transformed with a linear technology into one unit of non-storable output. The government can tax the consumers by means of a proportional tax on labor income $\tau_{t}$. The tax rate is constrained to be identical across consumers.

Thus, the intertemporal budget constraint faced by each consumer is:

$$
\sum_{t=0}^{T} \bar{q}_{t} c_{t} \leq b_{0}+\sum_{t=0}^{T} \bar{q}_{t}\left(1-\tau_{t}\right)\left(1-x_{t}\right)
$$

where $q_{t}$ is the present value at time zero of one unit of output at time $t$, i.e. $\bar{q}_{t}=\prod_{i=1}^{t} q_{i}$ where $q_{i}$ is the inverse of the gross interest rate in period 
$i$ and $q_{0}=1 ; b_{0}$ is the amount of government debt held by the consumer at the beginning of period zero. For simplicity throughout the paper we assume $b_{0}=0.3$ With identical tax rates for a 11 consumers, the superscript $i$ on $c$ and $x$ can be dropped since a 11 the consumers make the same choices of consumption and leisure.

The government can at no cost transform the output produced by the private sector in the two nonstorable public goods, $g$ and $f$. Thus, in each period the government chooses the level and the composition of public consumption, the tax rate and the amount of borrowing (lending) from the consumers. For simplicity, we assume that the government can issue only fixed interest debt with one period maturity. This assumption prevents each government from manipulating the term structure of public debt in order to bind its successors, as in Lucas-Stokey (1983). We also assume no default risk: each government is committed to honoring the debt obligations of its predecessors. ${ }^{4}$ Under the final hypothesis that the economy is closed to the rest of the world, the resource constraint (in per-capita terms) is given by:

$$
c_{t}+x_{t}+g_{t}+f_{t} \leq 1 ; \quad t: 0,1 \ldots T .
$$

In this economy there are two "political parties", denoted $D$ and $R$, which can hold office. The parties are the political representatives of different "pressure groups", i.e. of the different (groups of) consumers. Since a11 consumers make identical choices regarding consumption and leisure, the parties "care" identically about these variables, but they have different preferences about the composition of public consumption. Their preferences are as follows (the superscripts identify the party):

$$
\begin{aligned}
& w^{D}=E_{0}\left\{\sum_{t=0}^{T} \delta^{t}\left[u\left(c_{t}\right)+v\left(x_{t}\right)+h\left(g_{t}\right)\right]\right\} ; \\
& w^{R}=E_{0}\left\{\sum_{t=0}^{T} \delta^{t}\left[u\left(c_{t}\right)+v\left(x_{t}\right)+h\left(f_{t}\right)\right]\right\} .
\end{aligned}
$$

Thus, party $D$ is identified with the consumer (or "constituency") with $\alpha_{j}=1$, and party $R$ is identified with the consumer (or "constituency") with $\alpha_{i}=$ 0 . This assumption greatly simplifies the algebra. The more general case 
with arbitrary values of a for the two parties will be analyzed in Section 8 . We assume that the preferences of party $D$ and $R$ do not change over time and that a prohibitive barrier prevents the entry of a third party.

Elections are held at the beginning of each period. A "period" is thus defined as a term of office. The electoral results are uncertain: party $D$ is elected with probability $P$ and party $R$ with probability 1-P. For expositional purposes $P$ is temporarily assumed to be an exogenous constant: in Sections 6 and 7 we complete the model with a political equilibrium in which every consumer/voter rationally votes for her most preferred party.

The private sector is atomistic. Thus the "representative consumer" solves (2) and (3)]taking $\tau_{t}, g$ and $f$ as given. Since $\tau_{t}$ is the same for every consumer, the solution of this problem is characterized by:

$$
\begin{aligned}
& u_{c}\left(c_{t}\right)\left(1-\tau_{t}\right)=v_{x}\left(x_{t}\right) \\
& q_{t} u_{c}\left(c_{t}\right)=\delta E_{t} u_{c}\left(c_{t+1}\right)
\end{aligned}
$$

where $u_{C}$ and $v_{x}$ denote the derivative of $u(\cdot)$ and $v(\cdot)$ with respect to their arguments (the arguments of the functions $u(\cdot)$ and $v(\cdot)$ will be omitted when there is no possibility of confusion). In (7), the expectation reflects the uncertainty of consumers about the future tax policy due to their uncertainty about the identity of future governments.

\section{TAXES AND PUBLIC SPENDING FOR A GIVEN DEFICIT}

A crucial assumption of this paper is that a government cannot bind the taxation and expenditure policies of its successors; this is true whether the successor belongs to the same or to the opponent party. The only way in which the fiscal policy of the current administration can influence the actions of its successors is through the law of motion of public debt. Since here the optimal fiscal policy can be time inconsistent, the model is solved by means of dynamic programming. The solution is a sub-game perfect equilibrium of the game in which each government plays against its successors and "against" the private sector. It is convenient to separate the government's optimization problem into two stages: the intraperiod problem of choosing taxes and public 
consumption for a given fiscal deficit; and the intertemporal problem. of choosing the size of the deficit. Since the government objective function is time-separable, this separation into two stages simplifies the exposition but involves no loss of generality.

Each government maximizes its own objective function, either (4) or (5), under the constraints given by (3), (6) and (7). Inspection of the two parties' objective functions and of their constraints easily yields the following results: i) in any period, only one kind of public good is produced: party $D$ supplies only $g$ and party $R$ only $f .5$ ii) For a given $f$ iscal deficit, both parties choose the same tax rate and the same level of public consumption, although on different goods; thus private consumption and leisure are identical under either party. For a given deficit, the two parties differ only with respect to the desired composition of the public goods.

These two results, together with the resource constraint (3), enable us to rewrite the static optimization problem faced by the party in office as:

$$
\operatorname{Max}_{t} u\left(c_{t}\right)+v\left(x_{t}\right)+h\left(1-c_{t}-x_{t}\right)
$$

subject to:

$$
H\left(b_{t+1}, b_{t}, c_{t}, x_{t}\right) \equiv\left(c_{t}-b_{t}\right) u_{c}\left(c_{t}\right)+\delta E_{t} u_{c}\left(c_{t+1}\right) b_{t+1}-\left(1-x_{t}\right) v_{x}\left(x_{t}\right) \geq 0 .
$$

This problem is solved for given values of the debt at the beginning and end of period $t$, namely $b_{t}$ and $b_{t+1}$. Equation (9) has been obtained by substituting (6) and (7) into (2) to eliminate $\tau_{t}$. It represents the government budget constraint, as a function of $c_{t}, x_{t}, b_{t}$ and $b_{t+1}$. Needless to say, the government does not choose $x$ and $c$ directly: it chooses taxes and public spending, affecting $x$ and $c$ indirectly. Throughout the paper we will assume that the government's optimum is an interior point of its feasible set. The necessary first order conditions (if, say, party $D$ is in office) imp 7y:

$$
H_{x}\left(h_{g}-u_{c}\right)=H_{c}\left(h_{g}-v_{x}\right)
$$

where $\mathrm{H}_{\mathbf{i}}$ denotes the derivative of $\mathrm{H}$ with respect to the variable $i$. Through- 
out the rest of the paper we assume that the second order conditions of this problem, reported in Section 1 of the Appendix, are satisfied.

The first order conditions, namely equation (10) together with the constraints (3) and (9), implicitly define the optimal private and public consumption and leisure choices in period $t$ as a function of $b_{t}$ and $b_{t+1}$;

$$
c^{\star}\left(b_{t}, b_{t+1}\right), x^{\star}\left(b_{t}, b_{t+1}\right), g^{\star}\left(b_{t}, b_{t+1}\right), f^{\star}\left(b_{t}, b_{t+1}\right)
$$

Note that, recalling point (ii) on page 7 , we have $g^{\star}\left(b_{t}, b_{t+1}\right)=f^{\star}\left(b_{t}, b_{t+1}\right)$ for any $b_{t}, b_{t+1}$. With virtually no loss of generality we shall assume for the rest of the paper that at the optimum the labor supply function is upward sloping. 6

In Section 2 of the Appendix several useful results regarding the partial derivatives of $c^{\star}, x^{\star}, g^{\star}$ and $f^{\star}$ are established. For example it is shown that $c^{\star}$ and $x^{\star}$ are increasing in $b_{t}$. The intuition is that if $b_{t}$ increases more interests have to be paid in period $t$. With a given end of period debt $\left(b_{t+1}\right)$, the government is forced to reduce public consumption and to raise taxes. The private sector's response to the higher tax rates and to the larger initial public debt is to increase its consumption of both leisure and output.

The solution of this static optimization problem defines the indirect utility of both parties in period $t$ as a function of the debt at the beginning and at the end of the period. Let us indicate this function for the party in office as $R^{e}\left(b_{t}, b_{t+1}\right)$. This function is identical for both parties (since $g^{\star}=f^{\star}$ and both parties choose the same tax rate). Section 2 of the appendix proves the following:

Lemma 1

$\underline{R}^{e}\left(b_{t}, b_{t+1}\right)$ is continuous and differentiable, strictly decreasing in $b_{t}$ and strictly concave in both $b_{t}$ and $b_{t+1}$.

Thus, not surprisingly, the party in office gets disutility by inheriting debt from the past. The utility function of either party whenever it does not hold office can also be easily characterized. Specifically, letting $R^{N}\left(b_{t}, b_{t+1}\right)$ denote the utility function of either party if not elected in period $t$, we have: 


$$
\begin{gathered}
R^{N}\left(b_{t}, b_{t+1}\right)=u\left(c^{\star}\left(b_{t}, b_{t+1}\right)+v\left(x^{\star}\left(b_{t}, b_{t+1}\right)\right)=\right. \\
=R^{e}\left(b_{t}, b_{t+1}\right)-h\left(g^{\star}\left(b_{t}, b_{t+1}\right)\right)
\end{gathered}
$$

It is shown in Section 2 of the Appendix that $R^{N}(\cdot)$ is continuous and differentiable and it is strictly increasing in $b_{t}$. Thus, the party out of office benefits from the debt inherited from the past, since it makes the private sector wealthier in the current period.

\section{FISCAL POLICY UNDER A SOCIAL PLANNER}

In this section we characterize the solution of the intertemporal problem faced by an hypothetical social planner. This solution will serve as a benchmark to characterize the effects of the elections.

A social planner has two characteristics: a) she does not face elections, thus she is "reappointed" with probability 1 each period; b) she adopts as her preferences a weighted average of the preference of the citizens, (i.e. of equation (1)).

For expositional purposes, let us consider the effects of these two characteristics separately, starting with a). Thus we consider the case of a policymaker, say party $D$, that is certain of being reappointed each period. It is easy to verify that the optimal policy would always balance the budget, as in Lucas-Stokey (1983). However, since we rule out the possibility of making binding commitments, we are interested in the time-consistent fiscal policy, which may or may not coincide with the optimal policy. In the infinite horizon case, the social planner faces the following problem of dynamic programming:

$$
v^{e}\left(b_{t}\right)=\operatorname{Max}_{b_{t+1}}\left\{R^{e}\left(b_{t}, b_{t+1}\right)+\delta v^{e}\left(b_{t+1}\right)\right\}
$$

The first order conditions are:

$$
R_{2}^{e}\left(b_{t}, b_{t+1}\right)+\delta v_{b}^{e}\left(b_{t+1}\right)=0
$$




$$
v_{b}^{e}\left(b_{t}\right)=R_{1}^{e}\left(b_{t}, b_{t+1}\right)
$$

where $R_{j}^{e}(\cdot) i: 1,2$, denotes the partial derivative of $R^{e}(\cdot)$ with respect to its ith argument. From (13) and (14) it follows that in the steady state (i.e., for $b_{t}=b_{t+1}=$ b) we obtain:

$$
R_{2}^{e}(b, b)+\delta R_{1}^{e}(b, b)=0
$$

Substituting the expressions for $R_{2}^{e}(\cdot)$ and $R_{1}^{e}(\cdot)$ derived in section 3 of the Appendix, equation (15) simplifies to:

$$
\frac{\left(h_{g}-u_{c}\right)}{H_{c}} \cdot \delta u_{c c} c_{1}^{*} b=0
$$

Since generically $c_{1}^{\star} \neq 0$, equation (16) can be satisfied if and only if $b=0$; that is, if and only if in the steady state the government issues no debt. Thus, by using a simplified version of the proof given in Section 5 of the Appendix, we can prove the following result:

\section{Proposition 1}

The steady state level of government debt is zero and it is locally stable.

Thus, the optimal and time consistent policy coincide: the social planner would never issue public debt. ${ }^{7}$ A slight generalization of these arguments shows that analogous results hold for the finite horizon case.

We now turn to the problem of choosing the optimal composition of public expenditures. A social planner would choose a point on the "Pareto frontier" of the economy. Thus, she would maximize a weighted average of the utility functions of the citizens, namely:

$$
W^{S P}=\sum_{i=1}^{N} \lambda_{i} w^{i}=\sum_{t=0}^{\infty} \delta^{t}\left[u\left(c_{t}\right)+v\left(x_{t}\right)+\hat{\alpha h}\left(g_{t}\right)+(1-\hat{\alpha}) h\left(f_{t}\right)\right]
$$

where $\hat{\alpha}=\sum_{i=1}^{N} \lambda_{i} \alpha_{i}$ and $\lambda_{i}$ are arbitrary weights such that $\sum_{i=1}^{N} \lambda_{i}=1$. 
Obviously every point of the Pareto frontier is associated with a different choice of weights. It is easy to show that Proposition 1 applies identically to this case. Furthermore, the optimal composition of public expenditures satisfies the following condition:

$$
\hat{\alpha h_{g}}=(1-\hat{\alpha}) h_{f}
$$

Thus, the social planner equates the social marginal utility of the two types of public good. The optimal composition of the two goods depends on the choice of weights, $\hat{\alpha}$.

\section{ALTERNATING gOVERNMENTS IN THE TWO PERIOD MODEL}

To provide the basic intuition, we consider here the simplest possible case, with a time horizon of two periods. This case greatly simplifies the analysis by eliminating the private sector's uncertainty about the future tax policy. Consider the last period of the game: here both parties must collect the same tax revenue, since they inherit the same initial debt and are forced to leave the same end of period debt, namely 0 . Thus, in the first period (labeled period 0 ) consumers face no uncertainty about the tax rate of period 1. It follows that the interest rate is independent of the electoral outcome and of $P$. This in turn implies that the functions $R^{e}(\cdot)$ and $R^{N}(\cdot)$ defined in Section 3 are also independent of $P$.

Suppose that party $D$ holds office at the beginning of the first period. The amount of debt that this party chooses to leave to the following period $\left(b_{1}\right)$ can be found by solving the following problem:

$$
\operatorname{Max}_{b_{1}} V\left(b_{0}\right)=R^{e}\left(b_{0}, b_{1}\right)+\delta\left[P R^{e}\left(b_{1}, 0\right)+(1-P) R^{N}\left(b_{1}, 0\right)\right]
$$

Given that $b_{0}=0$, the first order condition can be written as:

$$
R_{2}^{e}\left(0, b_{1}\right)=-\delta\left[P R_{1}^{e}\left(b_{1}, 0\right)+(1-P) R_{1}^{N}\left(b_{1}, 0\right)\right]
$$

The left hand side of (20) can be interpreted as the marginal utility in 
period 0 of leaving debt to the future. We denote it by MV. The right hand side can be interpreted as the expected marginal cost of inheriting debt tomorrow, discounted to the present by $\delta$. More precisely, it is the negative of the discounted expected marginal disutility of next period debt. It is denoted by MC. Equation (20) implies that at the optimum MV = MC. This necessary condition is reproduced graphically in Figure 1 . MV is drawn with a negative slope since $R^{e}(\cdot)$ is strictly concave (see Lemma 1 ). MC is drawn as an upward sloping curve. This need not be the case, since $R^{N}(\cdot)$ is not necessarily concave. However, the slope of MC must always be greater than the slope of $M V$, since otherwise the second order conditions would be violated. Intuitively, consider a sma 11 movement from $\bar{b}_{1}$ in Figure 1 to $\vec{b}_{1}+\varepsilon, \varepsilon>0$ and "small". If at $\left(\bar{b}_{1}+\varepsilon\right)$ we have $M V>M C$, then $\bar{b}_{1}$ can not be an optimum, since a movement away from $\bar{b}_{1}$ increases total utility. Hence, MC must always intersect MV from below.

Equation (20), and the corresponding Figure 1, implicitly define the optimal end of period debt, $E_{1}$ as a function of $P$. We are interested in characterizing this functional relationship:

\section{Proposition 2}

$\bar{b}_{1}$ is a strictly decreasing function of $P$, for any value of $P$ in the interval $[0,1]$.

Proof: The partial derivative of MV with respect to $P$ is zero, since, as shown above, neither $R^{e}(\cdot)$ nor $R^{N}(\cdot)$ depend on $P$. By the same argument, and using (9), we have:

$$
\frac{\partial M C}{\partial \bar{P}}=-\delta\left(R_{1}^{e}\left(b_{1}, 0\right)-R_{1}^{N},\left(b_{1}, 0\right)\right)=-\delta h^{\prime} g_{1}^{*}\left(b_{1}, 0\right)
$$

In (21) $g_{1}^{\star}$ is the derivative of $g^{\star}$ respect to its first argument, $\bar{b}_{1}$. Lemma 2.1 in Appendix has established that $g_{1}^{\star}<0$. Thus, an increase in $\mathrm{P}$ shifts the MC curve upwards, say to the dotted curve of Figure 1. Since MC always intersects MV from below, this implies that $\bar{b}_{1}$ must fall with the increase of P.

The proof of this result is also suggestive of the intuition. The costs 


\section{EIGURE 1}

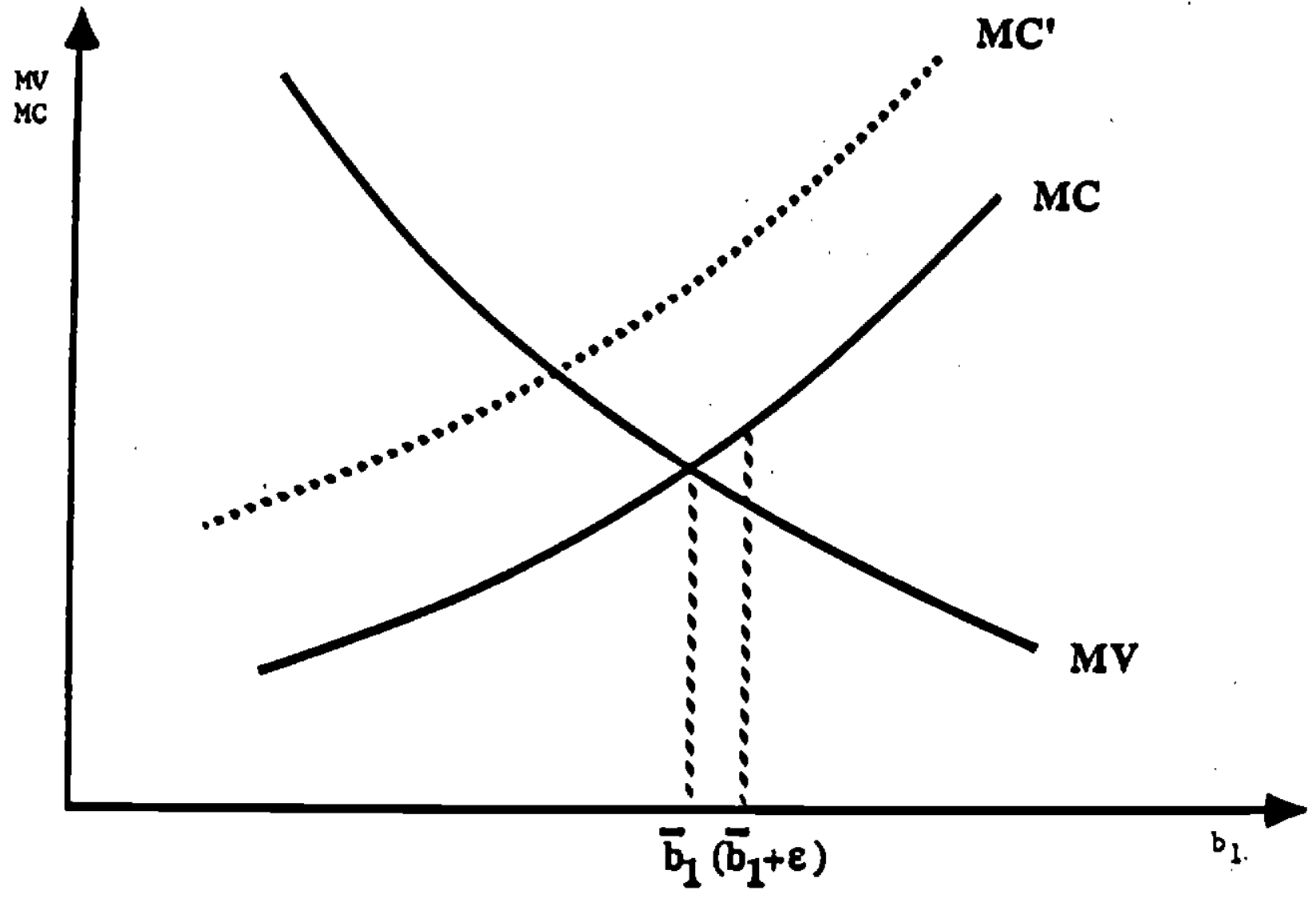


of leaving debt to the future arise from two sources: the tax distortions associated with the higher taxes tomorrow, and the reduced public consumption of tomorrow. However, the second cost only arises if the party currently in office is reappointed next period and it can choose the desired public good. Thus, the larger is the probability of being reelected, the more the party in office internalizes the cost of leaving debt to the future (i.e., the higher is $M C$ ). As a result, the larger is the probability of being reelected, the smaller is the debt left by each government to its successor. In more colorful terms, by leaving debt to the future, today's government can force its successor to "pay the bills" and spend less on the public good that is worthless for today's government.

Thus, Proposition 2 implies that the level of debt left to the last period $\left(\bar{D}_{1}\right)$ is larger in a democracy then with a social planner; namely the social planner would choose to balance the budget in both periods, while either one of the two parties chooses to run a budget deficit in the first period leaving a positive amount of debt to be repaid in the last period. In this sense the electoral uncertainty creates a sub-optimal deficit bias. This bias is stronger for the party with the smaller probability of reappointment.

\section{POLITICAL EQUILIBRIUM}

In this section we analyze voting behavior. Consider the elections held at the beginning of period 1 , and assume that, say, party $D$ is in office in period zero. Each voter votes for the party that is expected to deliver the highest utility in period 1 . Thus voter $i$ votes for party $D$ if and only if the expected utility with $D$ elected is not lower than the expected utility if $R$ is elected. Since both parties choose the same tax rate in period 1 , consumption and leisure are the same in period 1 regardless of the electoral outcome. Thus voter $i$ votes for party $D$ if and only if: 8

$$
\left[\alpha_{i} h\left(g^{\star}\left(0, b_{1}\right)\right)-\left(1-\alpha_{i}\right) h\left(f^{*}\left(0, b_{1}\right)\right]=h\left(g^{*}\left(0, b_{1}\right)\right)\left(2 \alpha_{i}-1\right) \geq 0\right.
$$

In deriving the right hand side of (22) we used the fact that $g^{\star}\left(0, b_{1}\right)=$ $f^{\star}\left(0, b_{1}\right)$. Since $h\left(g^{\star}\left(b_{1}\right)\right)>0$, condition (22) is equivalent to $a_{j} \geq \frac{1}{2}$. Let us assume that there is uncertainty about the distribution of voters 
preferences, namely about the distribution of the parameters $\alpha_{j}$ across consumers. In particular the preferences of the median voter are not known with certainty. 9 Given a known distribution over the preferences of the median voter and given (22) it follows that the probability that party 0 will be elected is given by:

$$
P=\left\{\text { prob. } \alpha_{m} \geq \frac{1}{2}\right\}
$$

where $\alpha_{m}$ is the value of $\alpha$ corresponding to the median voter. From (23) it is apparent that $P$ is a constant from the point of view of period zero. In particular, $P$ is not a function of $b_{1}$. Again, this result is due to the fact that, for any given level of debt inherited from period 0 , both parties choose the same level of taxes and public expenditure (although on different goods) in period 1 .

Note that the results implying policy convergence do not apply to this model. Since binding commitments are not available, and the horizon is finite, both parties can only credibly announce to the voters the timeconsistent fiscal policy characterized in the preceding sections. For example, party $D$ cannot convince the voters that if elected in period 1 it would supply a positive amount of $f$. Such an announcement would not be believed, because the voters know that the only time consistent policy for party $D$ is to set $f=0$ if elected; in fact the voters know that party $D$ maximizes the objective function (4) when in office. This argument is developed more in detail in Alesina (1986 and 1987).

Thus, we have shown that the equilibrium of Section 3 is unique and represents a time-consistent politico-economic equilibrium based on fully rational behavior of consumers/voters. Using propositions 1 and 2 , we are now ready to summarize the results obtained so far in the following:

\section{Proposition 3}

A democracy in which citizens disagree about the composition of public expenditures exhibits higher deficits and debt accumulation than an economy with a social planner who is appointed for ever. 


\section{THE INFINITE HORIZON CASE}

In the finite horizon case, debt in the final period of the game has to be repaid in full. In this section we show that our results generalize to the infinite horizon case, in which the debt need not be fully retired. In order to avoid the multiplicity of equilibria that inevitably arises in infinite horizon dynamic games, we restrict each government to selecting strategies contingent only on the stock of debt outstanding at the beginning of its term of office. This implies that we do not explore the reputational equilibria which may exist. We can characterize the solution only in the neighborhood of $P=\frac{1}{2}$, a particular case that greatly simplifies the analysis. If $P=\frac{1}{2}$, the optimization problem faced by the two parties is identical. Thus, the fiscal deficit, the tax rate and the level of public expenditure is the same for both parties: the only difference across parties is about which public good is supplied. As in the two period case, this fact eliminates consumers' uncertainties about future taxes so that $R^{e}(\cdot)$ and $R^{N}(\cdot)$ are independent of $P$. Intuitiveily the basic results should extend to any value of $P$, however the formal proof for the general case is much harder to establish.

We proceed assuming $P$ exogenous and then show that there exists a rational electoral equilibrium compatible with this assumption. The dynamic programming problem solved by the party in office is:

$$
V^{e}\left(b_{t}\right)=\operatorname{Max}_{b_{t+1}}\left\{R^{e}\left(b_{i}, b_{t+1}\right)+\delta P V^{e}\left(b_{t+1}\right)+\delta(1-P) V^{N}\left(b_{t+1}\right)\right\}
$$

where $V^{e}(\cdot)$ and $V^{N}(\cdot)$ are the value functions of the party if elected and if non-elected respectively. Thus:

$$
v^{N}\left(b_{t}\right)=R^{N}\left(b_{t}, b_{t+1}\right)+\delta\left(P v^{e}\left(b_{t+1}\right)+(1-P) v^{N}\left(b_{t+1}\right)\right)
$$

The first order conditions are:

$$
R_{2}^{e}\left(b_{t}, b_{t+1}\right)=-\delta\left[P V_{b}^{e}\left(b_{t+1}\right)+(1-P) V_{b}^{N}\left(b_{t+1}\right)\right]
$$

Equation (26) has exactly the same interpretation of (20) in Section 5: the left hand side of (26) represents the marginal utility of leaving debt to the 
future (MV); the right hand side is the expected marginal cost of inheriting debt tomorrow (MC). Thus, the diagram of Figure 1 still applies identically. MV is downward sloping since $\mathrm{R}^{\mathrm{e}}(\cdot)$ is concave. MC can be either upward sloping or downward sloping (since $V^{N}\left(b_{t}\right)$ is not necessarily concave), but has to intersect MV from below for (26) to characterize an interior opt imum. 10 From (26) we obtain:

\section{Proposition 4}

In a neighborhood of $P=\frac{1}{2}$, the steady state leve 1 of public debt is always positive and locally stable if the sufficient condition c. 2 of Lemma 2.1 in Section 2 of the Appendix is satisfied.

Proof: See Section 4 of the Appendix.

The condition alluded in the text is needed to insure that the total derivative of the level of the steady state debt on public expenditure is negative. Intuitively, an increase in the steady state level of debt requires an increase in the flow of interest payment to the private sector. To finance this interest flow the government is forced in general, to both tax more and spend less on public goods.

Thus, as in the two-period model, alternating governments which disagree over the composition of public consumption have a tendency to issue more public debt than the social planner. The intuition is still as in the previous section: since governments are not certain of winning the election they do not fully internalize the costs of leaving debt to their successors. In the two period model, these costs take the form of higher taxes and lower public consumption in order to repay the debt in the final period of the game. Here, instead, these costs correspond to the payment of interest on the stock of debt outstanding. 11

As in the previous section, we can ask what are the consequences on public debt of changing the probability of electoral outcomes. A local answer is given by the following result: 
Proposition 5

In a neighborhood of $P=\frac{1}{2}$, under the same condition of Proposition 4, and the additional sufficient condition:

$$
H_{b_{t+1}} \geq 0 \text { and } v_{b b}^{e}-v_{b b}^{N} \leq 0
$$

the stock of public debt issued by either party in the steady state is a decreasing function of the probability of that party winning the elections.

The proof is contained in Section 5 of the Appendix. 12

The intuition is the same as for the previous results. If $P$ rises, the party in office internalizes more of the costs of issuing debt; thus its policy is to reduce the stock of debt outstanding. This result reinforces the positive implications of the mode1, already discussed in Section 4: the debt policy of the party in office is influenced by its probability of winning the elections. The lower is this probability, the larger is the stock of debt issued in equilibrium and in the steady state by this party. 13

We finally show that there exists a political equilibrium which implies a constant $P=\frac{1}{2}$. At the beginning of period $t$, voter $i$ votes for party $D$ if and only if her lifetime utility is greater if in period $t D$ is elected rather than R. Suppose that both parties choose the same tax rate and the same level of public consumption) in period $t$ (even though they choose public goods of different kinds) so that they run the same deficit and leave the same amount of debt to the future. In this case the voters' expected utility from period $t+1$ to infinity is independent of which party is elected in period $t$. As a result, under this assumption, the voter's behavior is as described in the previous section: voter $i$ votes for party $D$ if and only if $\alpha_{j} \geq \frac{1}{2}$, as in Section 6 . Like in that section, the probability that party $D$ be elected in period $t$ is then:

$$
P=\operatorname{prob}\left(\alpha_{m} \geq \frac{1}{2}\right)
$$

Finally, assume that the distribution over the possible value of $\alpha^{m}$ is such that:

$$
\operatorname{prob}\left(\alpha_{m}>\frac{1}{2}\right)=\frac{1}{2}
$$


If (28) holds, then $P=\frac{1}{2}$; but in this case we showed that the time consistent policy for both parties is indeed to set the same tax rate and the same level of public consumption, although on different goods. Thus, we can conclude that there exists a distribution of the median voter's preferences supporting the economic equilibrium described in propositions 4 and 5 as a rational political equilibrium.

\section{EXTENSIONS}

In this section we extend the results presented above in several directions. First of all we generalize the objective functions of the two parties to:

$$
\begin{aligned}
& w^{D}=\sum_{t=0}^{T} \delta^{t}\left[u\left(c_{t}\right)+v\left(x_{t}\right)+\alpha h\left(g_{t}\right)+(1-\alpha) h\left(f_{t}\right)\right] \\
& w^{R}=\sum_{t=0}^{T} \delta\left[u\left(c_{t}\right)+v\left(x_{t}\right)+(1-\alpha) h\left(g_{t}\right)+\alpha h\left(f_{t}\right)\right]
\end{aligned}
$$

for any value of $1>\alpha>0$. In this case both parties assign positive utility to both public goods, although with different weights. Note that if $\alpha>1$ the results obtained with $\alpha=1$ are strengthened since party $D(R)$ attributes negative utility to good $f(g)$ : thus neither party ever would supply a positive amount of this good (an analogous argument holds for $\alpha<0$ ). To fix ideas, throughout this section we consider $1>_{\alpha>\frac{1}{2}}$; thus party $D(R)$ attributes more value to good $g(f)$ (the alternative case is completely symmetric). The coefficient $\alpha$ parameterizes the extent of the disagreement: the farther $\alpha$ is from $\frac{1}{2}$ the larger the disagreement.

The second extension of the model is that we allow for downward rigidity in the level of public consumption. We assume that a minimum level of both public goods must be provided. Thus we impose;

$$
f \geq k \quad \text { and } \quad g \geq k
$$

These constraints may reflect institutional or technological factors limiting the flexibility of the government in solving its problem. For example, a 
minimum level of defense spending might have to be provided or the level of social security cannot be reduced below a certain minimum. The case of different minimum levels of public consumption in the two goods complicates the algebra without qualitatively changing the results.

We rule out as uninteresting the case in which both constraints in (31) are binding. Then, the optimal composition of public consumption for, say, party $D$ is determined by the following first order conditions:

$$
\alpha h_{g} \geq(1-\alpha) h_{f}
$$

The first order condition for party $R$ is analogous to (32), except that a is replaced by $(1-\alpha)$. Condition (32) holds with a strict inequality if and only if the constraint is binding. Thus, if the constraint is not binding, the government equates the marginal utility of the two kinds of public goods.

The symmetry of this procedure suggests three simplifications which hold in the two period case and in the infinite horizon for $P=\frac{1}{2}$ : i) The two parties supply the same amount of the good they prefer and of the less preferred one (the superscript indicate which party supplies the good):

$$
g^{D}=f^{R} ; g^{R}=f^{D} ; g^{D}>f^{D} \text {. }
$$

ii) The tax rate and the size of the fiscal deficit chosen by the two parties is identical. iii) The constraint in (31) is binding for party $D$ if and only if it is also binding for party $R$.

It follows that the first order conditions of the static problem of the government are analogous to those stated in Section 3, and that Lemmas 1 and 2.1 (in Appendix) still apply identically. In particular, the difference between party D's utility if elected and if not elected can be expressed, using (33) as:

$$
R^{e}\left(b_{t}, b_{t+1}\right)-R^{N}\left(b_{t}, b_{t+1}\right)=(2 a-1)\left(h\left(g^{D}\right)-h\left(f^{D}\right)\right)
$$

which is positive by (33). The expression of $\left(R^{e}-R^{N}\right)$ for party $R$ is symmetric.

We now turn to the characterization of the dynamic equilibrium in the two period model. The extension to the infinite horizon for $P=\frac{1}{2}$ is 
straightforward and yields analogous results. The equilibrium is still characterized by the condition that the marginal utility of leaving debt to the future (MV) is equal to the marginal cost of inheriting debt from the past (MC) - - see (20) and Figure 1. Moreover, MV is stil1 as in Section 5. However, the relationship between $M C$ and $P$ now depends on whether or not the constraints stated in (31) are binding in the final period of the game. If these constraints are binding, then using (34) and assuming that party $D$ is in office in period 0 , we have:

$$
\frac{\partial M C}{\partial P}=\delta\left(R_{1}^{e},-R_{1}^{N}\right)=-\delta(2 \alpha-1) h_{g} g_{1}^{D}>0
$$

The results of Section 5 apply here: a decrease in the probability of being elected shifts MC to the right and thereby increases the debt issued in the first period. Uncertainty about the outcome of the election generates a deficit bias, as in the previous sections. Furthermore, note from (35) that the higher is $\alpha$, the higher is the effect of $P$ on the level of debt. Hence, for a given $P<1$, the larger is the disagreement, the larger is the deficit.

If instead the constraints in (31) are not binding, then we have:

$$
\frac{\partial M C}{\partial \bar{P}}=-\delta\left(R_{1}^{e}-R_{1}^{N}\right)=-\delta(2 \alpha-1)\left(h_{g} g_{1}^{D}-h_{f} f_{1}^{D}\right)>0
$$

Thus, for $P<1$, party $D$ would still choose not to balance the budget in period 0 (except in the particular case in which the right hand side of (36) happens to be 0 ). In this sense, the debt policy of the party in office differs from that of the social planner. However the government may now issue more or less debt than the social planner depending upon the sign of (36). In particular if $\frac{\partial M C}{\partial P}<0$ then we have a surplus bias, rather then a deficit bias. It can be shown that the sign of the inequality (36) depends upon the value of the third derivative of the function $h(\cdot) .14$ The intuition is as follows. If the constraints in (31) are not binding, then a higher public debt inherited from the past results in a reduction of expenditures on both public goods: $g_{1}^{D}<0$ and $f_{1}^{D}<0$. Hence, each government internalizes the cost of leaving debt to its successors, whether or not it expects to be reelected. If $\left|f_{1}^{D}\right|>\left|g_{1}^{D}\right|$, then the party in office (here $D$ ) reduces the non-preferred public good ( $f$ ) by more than the preferred one $(g)$ as initial debt increases. In this case, the marginal disutility of debt is higher if 
non-elected than if elected: $R_{1}^{e}-R_{1}^{N}<0$. As a result, in equilibrium the government runs a surplus rather than a deficit.

Consider the situation in which the constraint in (31) is just binding for, say, party 0 :

$$
\alpha h_{g}\left(g^{D}\right)=(1-\alpha) h_{f}(k)
$$

Equation (37) defines the threshold value of $k$ such that (31) is just binding. The implicit function theorem applied to (37) establishes that such value of $k$ is a decreasing function of $\alpha$. The same result applies to party R. It follows that the higher is $\alpha$, the more likely it is that the constraints in (37) are binding, and hence that a deficit bias results in equilibrium. Conversely, for a given $\alpha$, the larger is the minimum level of public goods (k) that has to be supplied, the more likely it is that the constraints in (37) are binding. Hence, the higher is $k$, the more likely it is that the party in office in the first period runs a fiscal deficit.

These results can be generalized to a stochastic setting in which each government is uncertain about the level of the constraint faced by its successors. Consider, for example, a situation in which $k$ is expected to rise in the future, so that future governments are perceived as very likely to be constrained. This may generate an incentive for the party currently in office to run a deficit, since future governments are likely to be prevented from repaying the deficit by reducing the public good that they value less (and that today's government values more). This contrasts with the optimal fiscal policy: as Lucas and Stokey (1983) have shown, the optimal policy here would be to run a surplus, not a deficit, so as to smooth the tax distortions over time in anticipation of the larger future public expenditures.

We can summarize the foregoing discussion in the following:

\section{Proposition 6}

The greater is the degree of polarization between the two parties, $\alpha$, the more the fiscal policy chosen by the two parties differs from that chosen by the social planner. Moreover, the greater the polarization, the more likely it is that the equilibrium exhibits a deficit bias. 


\section{CONCLUSIONS}

This paper shows how budget deficits and government debt can be used by each policymaker to influence the fiscal policy chosen by its successors. In this context, public debt becomes a strategic variable which links today's government to its successors.

If there is disagreement between political parties this strategic interaction generates a sub-optimal path of government debt. In particular, if the citizens disagree about the desired composition of public consumption, then, in general, the government has a tendency to overissue public debt relative to the case of full agreement or to the case in which future reappointment of the current government is certain. This tendency is stronger the greater is the degree of political polarization and of downward rigidity in public spending.

From a positive point of view, these results provide new insights on how to explain the current behavior of fiscal deficits in the United States and the difference in various countries' experience. In the United States the current administration has shown rather different views about the desired composition of government spending relative to the past and (presumably) relative to future administrations. This paper shows that in this case it is perfectly rational for the current administration to incur into deficits and debt accumulation to a much larger extent than previous administrations. An analogous result has been independently obtained in a very insightful paper by Persson and Svennson (1986). They consider the case of two policymakers with different views about the level rather than the composition of government expenditure. They show that the "conservative" policymaker (i.e. the one which likes less public expenditure) chooses to leave deficits in order to force its "liberal" successor to spend less. Conversely, the "liberal" policymaker would leave a surplus to its conservative successors. In addition, according to our results, different countries' experiences can be related to differences in the degree of political polarization, in the political stability, and in the flexibility of the government decision process concerning public consumption. More generally, this paper shows that fiscal deficits are the aggregate outcome of the political conflict between different groups of citizens. In this respect the positive predictions of our model coincide with those of some political science and sociological literature (for 
instance Lindberg and Mayer (1984) and the references quoted therein).

However, the methods of our analysis and our explanation differ sharply from those of that 1 ine of research. 


\section{APPENDIX}

1. Second order sufficient conditions

a) Static Optimum Problem: The second order sufficient conditions imply that the Hessian of the Lagrangian function corresponding to problem (8) is negative definite. They are, in addition to the strict concavity of $u(\cdot)$, $v(\cdot)$, and $h(\cdot)$ :

$$
\begin{aligned}
& \frac{\partial^{2} H}{\partial x^{2}}=H_{x x} \leq 0 ; \\
& \frac{\partial^{2} H}{\partial c^{2}}=H_{c c} \leq 0
\end{aligned}
$$

where $H(\cdot)$ is defined in (9).

b) Dynamic 0ptimum Problem: The conditions are that $H(\cdot)$ is quasiconcave with respect to all of its arguments. In addition to (A.1) and (A.2), we need the following sufficient conditions:

$$
\begin{aligned}
& \frac{a^{2} H}{a b_{t+1}^{2}}=H_{b_{t+1}} b_{t+1} \leq 0 \\
& 2\left(u_{c c}\right)^{2}-u_{c} u_{c c c} \geq 0 \\
& H_{x}^{2}+2 u_{c} H_{x x}\left(c_{t}-b_{t}\right) \leq 0
\end{aligned}
$$

Throughout the paper it is assumed that (A.1) - (A.5) always hold.

2. Lemma 2.1

(i) $g_{1}^{\star}<0$ and $x_{1}^{\star}>0$ if:

$$
u_{c}+u_{c c}\left(c_{t}-b_{t}\right) \geq 0
$$


(ii) $c_{1}^{\star}>0$ and $g_{1}^{\star}(b, b)+g_{2}^{\star}(b, b)<0$ for $b \geq 0$ if: (c.1) holds and if:

$$
\left|h_{g g}\right|<\left|\frac{H_{x x}\left(h_{g}-u_{c}\right)+v_{x x} H_{c}+u_{c c} H_{x}\left(h_{g}-v_{x}\right) / u_{c}}{H_{x}-H_{c}}\right|
$$

Proof: We apply the implicit function theorem to the following two equations 8 reproduced from the text:

$$
\begin{aligned}
& H(\cdot) \equiv\left(c_{t}-b_{t}\right) u_{c}\left(c_{t}\right)+\delta u_{c}\left(c_{t+1}\right) b_{t+1}-\left(1-x_{t}\right) v_{x}=0 \\
& G(\cdot) \equiv H_{x}\left(h_{g}-u_{c}\right)-H_{c}\left(h_{g}-v_{x}\right)=0
\end{aligned}
$$

Let $c_{1}^{\star}=\frac{\partial c_{t}}{\partial b_{t}}, c_{2}^{\star}=\frac{\partial c_{t}^{\star}}{\partial b_{t+1}}, G_{c}=\frac{\partial G}{\partial c_{t}}$, and so on. Then, by applying the implicit function theorem we obtain:

$$
\begin{aligned}
& {\left[\begin{array}{c}
c_{1}^{\star} \\
x_{1}^{\star}
\end{array}\right]=-\left[\begin{array}{ll}
G_{c} & G_{x} \\
H_{c} & H_{x}
\end{array}\right]-1\left[\begin{array}{l}
G_{b_{t}} \\
H_{b_{t}}
\end{array}\right]} \\
& {\left[\begin{array}{c}
c_{2}^{\star} \\
x_{2}^{\star}
\end{array}\right]=-\left[\begin{array}{ll}
G_{c} & G_{x} \\
H_{c} & H_{x}
\end{array}\right]-1\left[\begin{array}{l}
G_{b_{t+1}} \\
H_{b_{t+1}}
\end{array}\right]}
\end{aligned}
$$

Solving (A.6) and (A.7), and letting $\Delta=G_{x} H_{x}-G_{x} H_{C}$ we obtain:

$$
\begin{aligned}
& c_{1}^{\star}=-\left(H_{x} G_{b_{t}}-H_{b_{t}} G_{x}\right) / \Delta \\
& x_{1}^{\star}=-\left(G_{c} H_{b_{t}}-G_{b_{t}} H_{c}\right) / \Delta \\
& c_{2}^{\star}=G_{x} H_{b_{t+1}} / \Delta \\
& x_{2}^{\star}=-G_{c} H_{b_{t+1}} / \Delta
\end{aligned}
$$


Using the fact that $g_{j}^{\star}=-\left(c_{j}^{\star}+x_{j}^{\star}\right)$, we obtain:

$$
\begin{aligned}
& g_{1}^{\star}=\left[G_{b_{t}}\left(h_{x}-H_{c}\right)+H_{b_{t}}\left(G_{c}-G_{x}\right)\right] / \Delta \\
& g_{2}^{\star}=\left[H_{b_{t+1}}\left(G_{c}-G_{x}\right)\right] / \Delta \\
& g_{1}^{\star}+g_{2}^{\star}=\left[G_{b_{t}}\left(H_{x}-H_{c}\right)+\left(G_{c}-G_{x}\right)\left(H_{b_{t}}+H_{b_{t+1}}\right)\right] / \Delta
\end{aligned}
$$

Some algebra establishes that:

$$
\begin{aligned}
& G_{c}=-\left(u_{c c}+h_{g g}\right) H_{x}+h_{g g} H_{c}+\left(v_{x}-h_{g}\right) H_{c c} \\
& G_{x}=-\left(u_{c}-h_{g}\right) H_{x x}-h_{g g} H_{x}+\left(v_{x x}+h_{g g}\right) H_{c} \\
& G_{b_{t}}=u_{c c}\left(h_{g}-v_{x}\right) \\
& H_{c}=\left(c_{t}-b_{t}\right) u_{c c}+u_{c} \\
& H_{x}=-\left(1-x_{t}\right) v_{x x}+v_{x} \\
& H_{b_{t}}=-u_{c} \\
& H_{b_{t}+1}=\delta u_{c}\left(c_{t+1}\right)+\delta b_{t+1} u_{c c}\left(c_{t+1}\right) c_{1}^{\star}\left(b_{t+1}, b_{t+2}\right)
\end{aligned}
$$

We now use the sufficient conditions reported in Section 1 of the Appendix to sign these expressions. By using (A.1) and after some algebra, it can be shown that $\Delta>0$. Rewrite $G_{C}$ as:

$$
G_{c}=-u_{c c} H_{x}+h_{g g}\left(H_{c}-H_{x}\right)-\left(h_{g}-v_{x}\right) H_{c c}
$$

By manipulation of (10) and (6), it can be shown that $\mathrm{H}_{\mathrm{C}}-\mathrm{H}_{x}<0$. Using (A.1) it follows that $G_{C}>0$. Consider $\left(G_{C}-G_{X}\right)$ :

$$
G_{c}-G_{x}=-u_{c c} v_{x}+u_{c c} v_{x x}\left(g_{t}+b_{t}\right)-v_{x x} u_{c}\left(c_{t}-b_{t}\right)-\left(h_{g}-v_{x}\right) H_{c c}-\left(h_{g}-u_{c}\right) H_{x x}
$$

From (10), the sign of $\left(h_{g}-u_{c}\right)$ is the same as the sign of $H_{c}=u_{c}+u_{c c}\left(c_{t}-b_{t}\right)$.

26 
The sign is positive if $c>1$ in Lemma 2.1 holds. Hence, $G_{c}-G_{x}>0$. We then have $g_{1}^{\star}<0$. To show that $x_{1}^{\star}>0$, rewrite the numerator of $x_{1}^{\star}$ as:

$$
G_{b_{t}} H_{c}-G_{c} H_{b_{t}}=u_{c} h_{g g}\left(H_{c}-H_{x}\right)-u_{c} u_{c c} H_{x}-u_{c}\left(h_{g}-v_{x}\right) H_{c c}+u_{c c}\left(h_{g}-v_{x}\right) H_{c}
$$

The first two terms on the right hand side of (A.24) are positive. The last two terms can be rewritten as:

$$
\left(h_{g}-v_{x}\right)\left[-u_{c c}\left(u_{c}+u_{c c}\left(c_{t}-b_{t}\right)\right)+\left(c_{t}-b_{t}\right)\left(2\left(u_{c c}\right)^{2}-u_{c} u_{c c c}\right)\right]
$$

By (c.1) and (A.4), the expression inside the square brackets of (A.25) is non-negative. Hence, \}the right hand side of (A.24) is positive, which in turn implies $x_{1}^{\star}>0$. In order to show that $c_{1}^{\star}>0$, consider the numerator of $c_{1}^{\star}$ in (A.8):

$$
H_{b_{t}} G_{x}-H_{x} G_{b_{t}}=-u_{c}\left[\left(h_{g}-u_{c}\right) H_{x x}+v_{x x} H_{c}+h_{g g}\left(H_{c}-H_{x}\right)\right]-H_{x} u_{c c}\left(h_{g}-v_{x}\right)
$$

By (c.2), the right hand side of (A.26) is positive. Hence $c_{1}^{*}>0$. Note that, as emphasized in footnote 6 , condition c.1 holds if and only if the labor supply function is upward sloping.

Finally, recalling the previous discussion, in order to prove that $\mathrm{g}_{1}^{\star}=$ $g_{2}^{\star}<0$ in the steady state, we have to show only that $H_{b_{t}}+H_{b_{t+1}} \leq 0$ if $b_{t}=b_{t+1}=b_{t+2}$. From (A.20) and (A.21) it follows:

$$
H_{b_{t}}+H_{b_{t+1}}=-u_{c}\left(c_{t}\right)+\delta u_{c}\left(c_{t+1}\right)+\delta b_{t+1} u_{c c}\left(c_{t+1}\right) c_{1}^{\star}\left(b_{t+1}, b_{t+2}\right)
$$

If $b_{t}=b_{t+1}=b_{t+2}$, then $c_{t}^{\star}=c_{t+1}^{\star}$; thus (A.27) simplifies to:

$$
H_{b_{t}}+H_{b_{t+1}}=-(1-\delta) u_{c}+\delta b_{t+1} u_{c c} c_{1}^{*}
$$

which is negative if $c_{1}^{*}>0$ and $b_{t+1} \geq 0$.

\section{Proof of Lemma 1}

Continuity of $R^{e}(\cdot)$ follows from the fact that the maximization is 
performed on a compact feasible set, and from the continuity of $u(\cdot), v(\cdot)$ and $h(\cdot)$ (see the theorem of the maximum in Hildenbrand (1974)). Differentiability follows from the fact that $c^{\star}, x^{\star}$ and $g^{\star}$ are continuously differentiable, as implied by the application of the implicit function theorem to (10). Strict concavity can be proved as follows: Let $b_{t}^{\theta}=\theta b_{t}^{0}+(1-\theta) b_{t}^{1}, \quad b_{t}^{0} \neq b_{t}^{1}$,

$0<\theta<1$; let $b_{t+1}^{\theta}$ be similarly defined. We want to show that $R^{e}\left(b_{t}^{\theta}, b_{t+1}^{\theta}\right)>$ $\theta R^{e}\left(b_{t}^{0}, b_{t+1}^{0}\right)+(1-\theta) R^{e}\left(b_{t}^{1}, b_{t+1}^{1}\right)$. Let $c_{t}^{i}=c^{\star}\left(b_{t}^{i}, b_{t+1}^{i}\right)$, $x_{t}^{i}=x^{*}\left(b_{t}^{i}, b_{t+1}^{i}\right)$ be the values of $c_{t}, x_{t}$ chosen at the optimum, given $\left(b_{t}^{i}\right.$, $\left.b_{t+1}^{i}\right)$; consider $R^{e}\left(b_{t}^{\theta}, b_{t+1}^{\theta}\right)$ :

$$
\begin{gathered}
R^{e}\left(b_{t}^{\theta}, b_{t+1}^{\theta}\right)=u\left(c_{t}^{\theta}\right)+v\left(x_{t}^{\theta}\right)+h\left(1-c_{t}^{\theta}-x_{t}^{\theta}\right) \geq \\
\geq u\left[\theta c_{t}^{0}+(1-\theta) c_{t}^{1}\right]+v\left(\theta x_{t}^{0}+(1-\theta) x_{t}^{1}\right)+ \\
+h\left(1-\theta c_{t}^{0}-(1-\theta) c_{t}^{1}-\theta x_{t}^{0}-(1-\theta) x_{t}^{1}\right)
\end{gathered}
$$

(A.29) follows from the definition of $c_{t}^{\theta}, x_{t}^{\theta}$ and from the quasi-concavity of $H(\cdot)$. Moreover, by the strict concavity of $u(\cdot), V(\cdot)$ and $h(\cdot)$, the right hand side of (A.29) is strictly greater than:

$$
\begin{gathered}
\theta\left[u\left(c_{t}^{0}\right)+v\left(x_{t}^{0}\right)+h\left(1-c_{t}^{0}-x_{t}^{0}\right)\right]+(1-\theta)\left[u\left(c_{t}^{1}\right)+v\left(x_{t}^{1}\right)+h\left(1-c_{t}^{1}-x_{t}^{1}\right)\right]= \\
=\theta_{\theta} R^{e}\left(b_{t}^{0}, b_{t+1}^{0}\right)+(1-\theta) R^{e}\left(b_{t}^{1}, b_{t+1}^{1}\right)
\end{gathered}
$$

It follows that $R^{e}(\cdot)$ is strictly concave in both $b_{t}$ and $b_{t+1}$.

Finally, from the envelope theorem and from the first order conditions 
from which equation (10) in the text is derived we obtain:

$$
\begin{aligned}
& \frac{\partial R^{e}}{\partial b_{t}} \equiv R_{1}^{e}=\frac{\left(h_{g}-u_{c}\right)}{H_{c}} H_{b_{t}}<0 \\
& \frac{\partial R^{e}}{\partial b_{t+1}}=R_{2}^{e}=\frac{\left(h_{g}-u_{c}\right)}{H_{c}} H_{b_{t+1}}>0, \text { if } \cdot H_{b_{t+1}}>0 .
\end{aligned}
$$

4. Proof of Proposition 4

Equation (26) in the text implicitly defines $b_{t+1}$ as a function of $b_{t}$ and $P: b_{t+1}=B\left(b_{t}, P\right)$. We will use the following notation: $B_{1}=\frac{\partial B\left(b_{t}, P\right)}{\partial b_{t}}$ $B_{12}=\frac{\partial^{2} B\left(b_{t}, P\right)}{\partial b_{t} \partial P}$, and so on. We prove stability first. This involves

showing that $\left|B_{1}\right|<1$. By the envelope theorem:

$$
v_{b}^{e}\left(b_{t+1}\right)=R_{1}^{e}\left(b_{t+1}, b_{t+2}\right)
$$

Plugging (A.33) in (26) of the text, differentiating with respect to $b_{t}$ and then setting $b_{t}=b_{t+1}$, we obtain:

$$
R_{21}^{e}+R_{22}^{e} B_{1}+\delta P R_{11}^{e} B_{1}+\delta P R_{12}^{e}\left(B_{1}\right)^{2}+\delta(1-P) V_{b b}^{N} B_{1}=0
$$

where $R_{i j}^{e}$ denotes the second derivative of $R^{e}$ with respect to its $i$ th and $j$ th arguments. Solving (A.34) with respect to $B_{1}$, we find that both roots are positive and real, and that one lies inside and the other outside the unit circle. Specifically, the stable root is:

$$
B_{1}=-\frac{\left(R_{22}^{e}+\delta P R_{11}^{e}+\delta(1-P) V_{b b}^{N}\right)-\sqrt{D}}{2 \delta P R_{12}^{e}}
$$

where $D=\left(R_{22}^{e}+\delta P R_{11}^{e}+\delta(1-P) V_{b b}^{N}\right)^{2}-4\left(R_{12}^{e}\right)^{2} \delta P>0$ 
If the second order condition stated in footnote (12) holds, then it can be shown that the right hand side of (A.35) is always included in the open interval $(0,1)$. The root inside the unit circle is the solution to the dynamic programming problem (since $v^{e}(\cdot)$ is decreasing in $b_{t}$ ); thus the steady state is locally stable.

In order to prove that the steady state debt is positive, note that, with $P=\frac{1}{2}$ and using (24) $-(25)$ in the text, we obtain:

$$
V_{b}^{N}\left(b_{t+1}\right)=R_{1}^{N}\left(b_{t+1}, b_{t+2}\right)+B_{1}\left(b_{t+1}\right)\left(R_{2}^{N}\left(b_{t+1}, b_{t+2}\right)-R_{2}^{e}\left(b_{t+1}, b_{t+2}\right)\right.
$$

Then, substitute (A.33) and (A.36) into (25) of the text and use (11) to simplify. In the steady state, we obtain:

$$
R_{2}^{e}+\delta R_{1}^{N}-\delta B_{1} h_{g} g_{2}^{\star}+\delta P h_{g}\left[g_{1}^{\star}+B_{1} g_{2}^{\star}\right]=0
$$

Let us proceed by contradiction and suppose that, the steady state level of public debt is 0 . Equations (A.20) (A.21) together with (A.31) imply that $R_{2}^{e}=-\delta R_{1}^{e}$. Substituting this expression in (A.37) and using (11) of the text again to simplify, we obtain:

$$
(P-1)\left(g_{1}^{\star}+B_{1} g_{2}^{\star}\right) \delta h_{g}=0
$$

By Proposition 1, if $c .1$ and $c .2$ of Lemma 2.1 hold then $g_{1}^{\star}+g_{2}^{\star}<0$ and $g_{1}^{\star}<$ 0 . Since $B_{1}<1,(A .38)$ then yields a contradiction, unless $P=1$. A slightly more elaborate argument (which again makes use of equation (A.38)) also rules out the possibility of a negative debt in the steady state. Needless to say, (A.38) is satisfied if and only if $P=1, i . e$. in the case of the social planner.

\section{Proof of Proposition 5}

In order to prove this result we first need this preliminary lemma. 


$$
\frac{\partial V_{b}^{N}}{\partial P}<0 \text { if } H_{b t+1} \geq 0 \text { and } v_{b b}^{e}-v_{b b}^{N} \leq 0
$$

\section{Proof:}

$$
\text { Using (11) and (A.36): }
$$

$$
\frac{\partial V_{b}^{N}}{\partial P}=\left(R_{2}^{N}-R_{2}^{e}\right) B_{12}=-h_{g} g_{2}^{\star} B_{12}
$$

Note that $B_{12}$ is implicitly defined by equation (25) with $P$ replaced by (1-P) since we are now considering the party out of office, while (25) in the text was derived assuming $D$ in office (and $D$ is reelected with probability $P$ ). From (26) in the text we then have:

$$
R_{2}^{e}\left(b_{t}, b_{t+1}\right)+\delta(1-P) V^{e}\left(b_{t+1}\right)+\delta P V_{b}^{N}\left(b_{t+1}\right)=0
$$

Differentiate $(A .40)$ with respect to $b_{t}$ :

$$
R_{21}^{\mathrm{e}}+R_{22}^{\mathrm{e}} \mathrm{B}_{1}+\delta(1-P) \mathrm{V}_{b b}^{\mathrm{e}} \mathrm{B}_{1}+\delta P V_{b b}^{\mathrm{N}} \mathrm{B}_{1}=0
$$

Applying the implicit function theorem to (A.41):

$$
B_{12}=\frac{d B_{1}}{d P}=-\frac{\delta B_{1}\left(V_{b b}^{N}-V_{b b}^{e}\right)}{R_{22}^{e}+\delta(1-P) V_{b b}^{e}+\delta P V_{b b}^{N}}
$$

Differentiating (A.32), we obtain $R_{22}^{e_{2}}<0$ and $R_{21}^{e}>0$. Hence, by the condition in footnote (12) (with $P$ replaced by $(1-P)$ ), the denominator on the right hand side of $(A .42)$ is negative. As a result, if $v_{b b}^{e}-v_{b b}^{N}<0$, then $\mathrm{B}_{12}>0$. Moreover, if $\mathrm{H}_{\mathrm{b}_{t+1}}>0$ and if $\mathrm{c} .1$ holds, then $\mathrm{g}_{2}^{\star}>0$ (see Section

2 of the Appendix). Equation (A.39) then implies that $\frac{\partial V_{b}^{N}}{\partial P}<0$.

We now turn to proove Proposition 5. We want to show that 
$\frac{\partial M V}{\partial P}=0$ and $\frac{\partial M C}{\partial P}>0$, where $M V$ and $M C$ correspond to the left and right hand side of (26) in the text, respectively. If this holds and since the slope of MV is algebraically lower than the slope of MC, the equilibrium level of public debt then falls if $P$ rises. (See Figure 1 in the text).

The fact that $\frac{\partial M V}{\partial P}=0$ follows because, with $P=\frac{1}{2}, R^{e}(\cdot)$ is independent of $P$. In order to prove that $\frac{\partial M C}{\partial P}>0$, we differentiate the right hand side of (25), and we obtain:

$$
\frac{\partial M C}{\partial P}=-\delta\left[V_{b}^{e}\left(b_{t+1}\right)-V_{b}^{N}\left(b_{t+1}\right)+(1-P) \frac{\partial V_{b}^{N}\left(b_{t+1}\right)}{\partial P}\right]
$$

Consider now the first two terms on the right hand side of (A.43). Using (11), (A.33) and (A.36), they can be rewritten as:

$$
v_{b}^{e}-v_{b}^{N}=\left(g_{1}^{\star}+B_{1} g_{2}^{\star}\right) h_{g}
$$

By Lemma 2.1, if $c .1$ and $c .2$ hold, then $g_{1}^{\star}+g_{2}^{\star}<0$ and $g_{1}^{\star}<0$. Since $0<B_{1}<1$, the right hand side of (A.43) is negative. This, together with Lemma 5.1 and (A.41), implies that $\frac{\partial M C}{\partial P}>0$.

Q.E.D. 
Footnotes

*We are grateful to Richard Cantor, Daniel Heyman, John Van Huyck, John Lott, Susan Vitka and to several of our colleagues at Carnegie-Mellon and UCLA for helpful discussions and comments on a preliminary version of this paper.

1. There exists a large literature on the political economy of fiscal policy. Earlier contributions such as Niskanen (1971), Buchanan-Wagner (1979), Brennan-Buchanan (1981) and those surveyed by Muller (1979), Brunner (1979) and Peacock (1979) were based upon the questionable notion of "fiscal illusion" and voters' irrationality. This assumption can be easily criticized theoretically; in addition Cameron (1978) shows that even empirically this assumption does not perform we11. More recent contributions have studied the "size of government" in general equilibrium models based upon full rationality, for example see Meltzer-Richard (1981), Becker (1985), Lindbeck (1985), Lindbeck-Weibu11 (1985). These models are static: thus they do not address the issue of public debt and of deficits. Cukierman-Meltzer (1986) have recently provided a rational politico-economic model of public debt. In their mode1, unlike in ours, public debt is used for intergenerational transfers, taxes are nondistortionary, and the median voter theorem applies.

2. Persson-Svensson (1986) have independently developed a model which captures a similar idea and is a natural companion to ours. Their paper differs from ours in the following respects: (i) they focus on the disagreement about the level of public expenditures, whereas we concentrate on disagreement about its composition. (ii) they consider a two-period model in which the current government is sure that it will not be reappointed, while we have a probabilistic change of government and we study both a two period and an infinite horizon mode1; (iii) they do not explicitly consider voting behavior, while we develop a voting equilibrium compatible with the economic equilibrium; (iv) they consider a small open economy, thus they assume an exogenously given world interest rate; we instead consider a closed economy, thus the interest rate is endogenously determined. The result of the present paper and those of Persson and Svensson (1986) are briefly compared in the conclusion.

3. Our results generalize to arbitrary values of $b_{0}$. (See also footnote 
7). The general results are available from the authors; they were enclosed in an earlier version of this paper.

4. The issue of government debt repudiation has been recentiy addressed by Bental-Kantorowicz-Peled (1986), and Grossman-Van Huyck (1986).

5. Throughout the paper we disregard the possibility of "cooperation" between the two parties. Presumably both parties could benefit by agreeing to compromise to a certain constant composition of public spending. This agreement could be sustained as a sub-game perfect equilibrium by means of reputational strategies as described in a different context by Alesina (1986, 1987).

6. It can be shown that the condition for an upward sloping labor supply function is:

$$
u_{c}+u_{c c}\left(c_{t}-b_{t}\right) \geq 0
$$

This assumption is adopted for simplicity of exposition. All our results generalize to the case of a downward sloping labor supply at the optimum if a very weak sufficient condition is satisfied. This condition is:

$$
\begin{aligned}
& {\left[\left(h_{g}-v_{x}\right) u_{c c}\left(H_{c}-H_{x}\right)\right\}+\left\{u_{c}\left(u_{c c} H_{x}+v_{x x} H_{c}\right)\right\}} \\
& +\left\{u_{c}\left(h_{g}-v_{x}\right)\left[u_{c c c}\left(b_{t}-c_{t}\right)-2 u_{c c}\right]\right\} \geq\left\{\left(u_{c}-h_{g}\right)\left\{v_{x x x}(1-x)-2 v_{x x}\right]\right\} .
\end{aligned}
$$

It can be shown (see Lemma 2.1 in Appendix) that the three terms on the right hand side are all positive, if the second order conditions of problem 8 are satisfied. Thus we require that these three terms dominate the left hand side (which is also positive).

7. If $b_{0} \neq 0$, the optimal and the time consistent policies need not be the same. (See Lucas-Stokey (1983), footnote 2 page 64). The time consistent policy is to run a surplus (if $b_{0}>0$ ) or a deficit (if $b_{0}<0$ ) until the condition of zero outstanding debt is reached. The time inconsistency of the optimal policy can be explained as in Rogers (1986): If $b_{0} \neq 0$, then the consumers carry a positive (or negative) amount of wealth to subsequent periods. The elasticity of labor supply is different before and after consumers have committed to a saving decision. This difference generates an incentive for the government to "surprise" the private sector with an unexpected change of tax policy and hence makes the optimal policy time inconsistent. As it will be apparent in the next sections of the 
paper, our positive results on the deficit bias hold irrespectively of the value of $b_{0}$.

8. For simplicity, and with no loss of generality we assume that indifferent voters vote for party $D$. We are also assuming that the costs of voting are zero and everybody votes. Minor changes of notation would allow us to consider the case in which indifferent voters randomize their ballot or do not vote.

9. An additional source of uncertainty about electoral results can arise from an uncertain number of abstensions. If there is uncertainty about the distribution of the perceived costs of voting by different voters, there would be uncertainty about electoral results even if the value of $\alpha_{i}$ were known for each consumer. On the costs of voting see for example Ledyard (1984).

10. The condition that MC intersects MV from below can be stated formaliy as:

$$
\mathrm{R}_{21}^{\mathrm{e}}+\delta\left(\mathrm{PV} \mathrm{bb}_{\mathrm{b}}^{\mathrm{e}}+(1-\mathrm{P}) \mathrm{V}_{\mathrm{bb}}^{\mathrm{N}}\right)<0 \text {. }
$$

11. This result has implications for the "size of government". An increase in the steady state of debt in general requires an increase in fiscal revenues to finance higher interest payments. Under very general conditions, the size of government as measured by the amount of fiscal revenues is higher in the two-party system than in the social planner case. Proof of this statement is available from the authors.

12. The condition in the text of Proposition 5 is only sufficient, and could be weakened at the price of some additional cumbersome computations. This condition can be interpreted as follows: the requirement that $\mathrm{H}_{b_{t+1}} \geq 0$ insures that the government does lot decrease its gross cash flows by issuing one additional unit of public debt--i.e., that $\frac{\partial q_{t} b_{t+1}}{\partial b_{t+1}}>0$, The requirement that $v_{b b}^{e}-v_{b b}^{N} \leq 0$ is related (but not equivalent) to the condition that $g^{\star}$ be a concave function of $b_{t}$ and $b_{t+1}$-- since if $P=\frac{1}{2}$ $v^{e}-v^{N}=h\left(g^{\star}\left(b_{t}, b_{t+1}\right)\right)$.

13. Note that if $P \neq \frac{1}{2}$ the steady state level of debt would be different for the two parties. Namely, if $P<\frac{1}{2}$, the level of debt that party $D$ would choose in the steady state and when in of fice is higher than the corresponding level for party $R$. This suggests that if $P \neq \frac{1}{2}$ one should 
observe a change of direction in the trend of debt whenever a new party is elected. Presumably, the fluctuations of debt would be bounded between these two steady states.

14. Since $g^{D}>f^{D}$ and since from (32):

$$
g_{1}^{D}=\frac{1-\alpha}{\alpha} \frac{h_{f f}}{h_{g g}} \cdot f_{1}^{D},
$$

it follows that $\frac{\partial M C}{\partial P}<0$ if $h_{g g g} \leq 0$, and $\frac{\partial M C}{\partial P}>0$ if $h_{g g g}>0$ and sufficiently large. In the former case, the government runs a surplus; in the second one a deficit. 


\section{References}

Alesina, Alberto (1986) "Credibility and Policy Convergence in a Two-Party System with Rational Voters" mimeo.

(1987) "Macroeconomic Policy in a Two-Party System as a

Repeated Game" Quarterly Journal of Economics, forthcoming.

Barro, Robert (1979) "On the Determination of the Public Debt" Journal of Political Economy, 87, 940-7.

(1985) "Government Spending, Interest Rates, Prices and Budget

Deficits in the United Kingdom, 1730-1918" working paper, University of Rochester.

(1986) "U.S. Deficits since World War I" the Scandinavian Journal of Economics, 88, 193-222.

(1987) "Macroeconomics" John Wiley and Sons, New York 2nd

Edition.

Becker, Gary, (1985) "Public Policies, Pressure Groups and Deadweights

Costs" Journal of Public Economics, 28, 329-47.

Bental, Benjamin, Devorah Kantorowicz, Dan Peled (1986) "Should Government Debt be Safe? An Analysis of Debt Repudiation" mimeo, November.

Brennan, Geoffrey and James Buchanan (1980) "The Power to Tax" Cambridge University Press, Cambridge, England.

Brock, William and Stephen Turnovsky (1980) "Time Consistency and Optima? Government Policy in a Perfect Foresight Equilibrium" Journal of Public Economics, 13, 183-212.

Brunner, Karl (1978) "Reflections on the Political Economy of Government:

The Persistent Growth of Government" Schweizerische Zeitschrift

Volkwirtschaft und Statis, (September) 649-80.

Buchanan, James and Richard Wagner (1977) "Democracy in Deficit" Academic

Press, New York, N.Y.

Cameron, David (1978) "The Expansion of the Public Economy: A Comparative Analysis" American Political Science Review, 72, 1243-61.

Cukierman, Alex, and Allan Meltzer (1986) "A Political Theory of Government

Debt and Deficits in a Neo Ricardian Framework" mimeo (November).

Grossman, Herschel and John Van Huyck (1986) "Sovereign Debt as a Contingent

Claim: Excusable Default, Repudiation and Reputation" Brown University working paper No. 85-17, August. 
Hildenbrand, Wernes (1974) "Core and Equilibria of a Large Economy" Princeton University Press, Princeton, N.J.

Lindbeck, Assar (1985) "Redistribution Policy and the Expansion of the

Public Sector" Journal of Public Economics, 28, 3019-28.

Lindbeck, Assar and Jorgen Weibu11 (1985) "Balance - Budget Redistribution

as Political Equilibrium" Institute for International Economic Studies,

Discussion Paper (November).

Lindberg, Leon and Charles Maier (1985) (ed.) "The Politics of Inflation and

Economic Stagnation" Brookings Institution, Washington.

Lucas, Robert (1986) "Principles of Fiscal and Monetary Policy" Journal of

Monetary Economics, January.

Lucas, Robert and Nancy Stokey (1983) "Optimal Fiscal and Monetary Policy in an Economy without Capital" Journal of Monetary Economics, 12, 55-93.

Meltzer, Allan and Scott Richard (1981) "A Rational Theory of the Size of

Government" Journal of Political Economy, 89, 914-27.

Mueller, Dennis (1979) "Public Choice" Cambridge University Press,

Cambridge England.

Niskanen, William (1971) "Bureaucracy and Representative Government"

Aldine-Atherton, Chicago, Illinois.

Persson, Torsten and Lars Svennson (1984) "Time-Consistent Fiscal Policy and

Government Cash-Flow" Journal of Monetary Economics, 14, 365-74. and (1986) "Checks and Balances on the Government Budget"

mimeo (November).

Peacock, Alan (1979) "Economic Analysis of Government and Related

Theories" St. Martin, New York, NY.

Rogers, Carol (1986a) "The Effects of Distributive Goals on the Time-

Inconsistency of Optimal Taxes" Journal of Monetary Economics, 17, 251-

69.

(1986b) "Time-Consistency and the Maturity Structure of

Government Debt" mimeo. 